\section{Growing Conditions Alter the Relationship Between SPAD-501 Values and Apple Leaf Chlorophyll}

\author{
Richard J. Campbell', Kendrick N. Mobley', Richard P. Marini', \\ and Douglas G. Pfeiffer ${ }^{3}$ \\ Virginia Polytechnic Institute and State University, Blacksburg, \\ VA 24061
}

\section{Additional index words. acetone extraction, Malus domestica, specific leaf weight}

Abstract. The relationship between SPAD-501 meter readings (SPAD) and total chlorophyll content (TCHL) was evaluated for 'Delicious' apple (Malus domestica Borkh.) leaves grown in various environments. Regression models were developed between SPAD and TCHL for each of six separate experiments and were evaluated for statistical coincidence. SPAD was linearly related in a positive manner to TCHL in five of the six experiments; however, models differed between experiments, particularly between field- and greenhouse-grown trees. Thus, the relationship between SPAD and TCHL must be determined for each experiment.

The SPAD-501 portable leaf greenness meter (Minolta Corp., Ramsey, N.J.) nondestructively measures leaf greenness. A positive linear relationship has been demonstrated between SPAD measurements and total extracted chlorophyll (TCHL) for a range of plant species (Yadava, 1986; Marquard and Tipton, 1987). These studies indicated the need to develop separate relationships for each plant species and individual meter. Our preliminary studies with the SPAD suggested that the relationship between SPAD and TCHL may vary within a species, depending on the growing conditions. The objective of this study was to evaluate the influence of various growing conditions on the relationship between the SPAD and TCHL for apple leaves.

The study consisted of six experiments with 'Delicious'/MM.111. Trees were grown under diverse conditions in the same year or under similar conditions in consecutive years. Ranges in TCHL were achieved by encouraging elevated populations of European red mite [ERM; Panonychus ulmi (Koch)], or twospotted spider mite [TSM; Tetranychus urticae (Koch)], and by varying $\mathrm{N}$ fertilization.

Greenhouse; $\mathrm{N}$ and mite levels (Expts. 1 and 2). One-year-old trees were grown in the greenhouse during the summer in 3.7-liter containers in a medium of equal parts (by volume) of peat, perlite, and vermiculite. In 1987, a range of chlorophyll was achieved with a factorial arrangement of two $\mathrm{N}$ levels ( 0 and $40 \mathrm{mg} \mathrm{N} /$ tree per week) and four ERM populations $(0,300,900$, and 1500 mite days/ leaf). In 1988, there were three $\mathrm{N}$ levels $(0$,

Received for publication 1 May 1989. The cost of publishing this paper was defrayed in part by the payment of page charges. Under postal regulations, this paper therefore must be hereby marked advertisement solely to indicate this fact.

'Graduate Student, Dept. of Horticulture.

${ }^{2}$ Associate Professor, Dept. of Horticulture.

${ }^{3}$ Associate Professor, Dept. of Entomology.
20, and $40 \mathrm{mg} \mathrm{N} /$ tree per week) and three ERM populations $(0,1000$, and 2000 mite days/leaf). The experimental designs were randomized complete blocks with two and six single-tree replicates per treatment in 1987 and 1988, respectively.

Field; mite population (Expts. 3 and 4). In Apr. 1987, 40 2-year-old 'Redchief Delicious'/MM.111 trees were planted at a spacing of $2 \times 3 \mathrm{~m}$ at the Virginia Polytechnic Inst. and State Univ. Horticultural Research Farm. Trees were grown according to standard recommendations, except ERM populations were allowed to develop on 20 randomly selected trees, while the remaining trees were kept mite-free. Mite populations were monitored weekly on one leaf per tree, and mites were removed or added to maintain mite levels of $\approx 0$ and 3000 mite days/ leaf on 20 trees per treatment. The experiment was repeated in 1988.
Greenhouse; mite population (Expts. 5 and 6). 'Imperia1 Delicious'/MM.111 trees were placed in a greenhouse in Apr. 1988 (Expt. 5) and June 1988 (Expt. 6) and grown as described for Expts. 1 and 2. Twospotted spider mites (> 2000 mite days/leaf) were allowed to develop on one leaf per tree for 10 trees per experiment, while another 10 trees were kept mite-free. The designs were completely randomized.

In each experiment, following accumulation of desired mite levels, three SPAD measurements $\left(37.8 \mathrm{~mm}^{2}\right.$ total measurement area) were averaged per leaf to represent one observation. Immediately following SPAD measurement, four disks per leaf $\left(1.2 \mathrm{~cm}^{2}\right.$ total area) were removed with a hole punch, pooled, and macerated in $10 \mathrm{ml}$ of cold $80 \%$ acetone with a Power Control Unit (Kinematica, Luzern, Switzerland). Chlorophyll suspensions were kept on ice and in the dark between each of the remaining steps. Samples were centrifuged at $3020 \times g$ for 5 min, and absorbance was measured on a UV-visible recording spectrophotometer (Shimadzu Corp., Columbia, Md.) at 645 and $663 \mathrm{~nm}$. Total chlorophyll content concentrations were determined by the method of Arnon (1949) and expressed on a leaf-area basis. Leaf area was measured with a LICOR (LI-3000, LI-COR, Lincoln, Neb.) portable leaf area meter, and leaves were dried at $60 \mathrm{C}$ for $72 \mathrm{hr}$ for determination of specific leaf weight (SLW). For each experiment, linear regression was used to evaluate the relationship between SPAD and TCHL. Differences between regression equations were evaluated using indicator variables in multiple regression analysis (Montgomery and Peck, 1982).

SPAD and TCHL were linearly related in a positive manner in five of the six experiments. In 1987, the greenhouse- and fieldgrown leaf sets (Expts. 1 and 3 ) yielded different models (Fig. 1). The range in SPAD

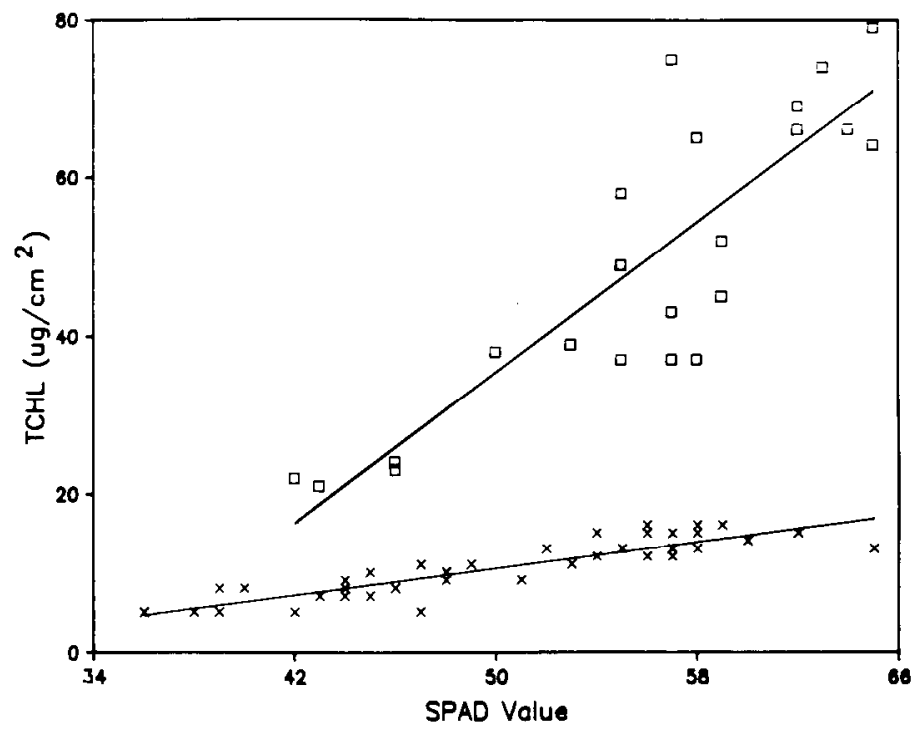

Fig. 1. Relationship between the SPAD-501 meter (SPAD) and total extracted chlorophyll (TCHL) for leaf sets grown under greenhouse $\left(\mathrm{X}-\mathrm{TCHL}=-10.3 \pm 0.42 \mathrm{SPAD}, R^{2}=0.79\right)$ and field conditions $\left(\square-\mathrm{TCHL}=-83.0+2.37 \mathrm{SPAD}, R^{2}=0.74\right)$. 
Table 1. Relationship between the SPAD-501 meter (SPAD) and total extracted chlorophyll (TCHL) for 'Imperial Delicious' apple leaves grown under various experimental conditions.

\begin{tabular}{|c|c|c|c|c|c|c|c|c|c|}
\hline \multirow[b]{2}{*}{ Experiment } & \multirow[b]{2}{*}{ Regression equation } & \multirow[b]{2}{*}{$\mathrm{P}>\mathrm{F}$} & \multirow[b]{2}{*}{$R^{2}$} & \multicolumn{2}{|c|}{$\begin{array}{c}\mathrm{SLW}^{y} \\
\left(\mathrm{mg} \cdot \mathrm{cm}^{2}{ }^{2}\right)\end{array}$} & \multicolumn{2}{|c|}{ SPAD } & \multicolumn{2}{|c|}{$\begin{array}{c}\text { TCHL } \\
\left(\mu \mathrm{g} \cdot \mathrm{cm}^{-2}\right)\end{array}$} \\
\hline & & & & Min & Max & Min & Max & Min & $\operatorname{Max}$ \\
\hline 1. Greenhouse 1987 & TCHL $=-10.3+0.42$ SPAD a & 0.0001 & 0.79 & 5.5 & 6.8 & 36 & 64 & 4.8 & 15.0 \\
\hline 2. Greenhouse 1988 & $\mathrm{TCHL}=-10.6+0.79$ SPAD $\mathrm{b}$ & 0.0001 & 0.59 & 5.0 & 6.7 & 34 & 55 & 14.2 & 40.0 \\
\hline 3. Field 1987 & $\mathrm{TCHL}=-83.0+2.37$ SPAD $\mathrm{c}$ & 0.0001 & 0.74 & 10.0 & 13.1 & 42 & 64 & 20.6 & 80.0 \\
\hline 4. Field 1988 & TCHL $=20.4+0.61$ SPAD d & 0.203 & 0.04 & 10.2 & 12.5 & 52 & 67 & 40.0 & 80.0 \\
\hline 5. Winter $1988^{x}$ & $\mathrm{TCHL}=-25.7+1.05$ SPAD b & 0.008 & 0.61 & 5.8 & 8.6 & 46 & 58 & 13.9 & 34.9 \\
\hline 6. Summer $1988^{x}$ & TCHL $=-22.9+1.01$ SPAD $b$ & 0.006 & 0.64 & 6.8 & 7.8 & 43 & 53 & 19.5 & 31.8 \\
\hline
\end{tabular}

${ }^{2}$ Separation of regression models with indicator variables by multiple regression.

'Specific leaf weight.

'Trees grown under greenhouse conditions in the winter and summer, respectively.

readings was similar in both sets, but TCHL measurements were quite different. Under greenhouse conditions, TCHL levels remained below $20 \mu \mathrm{g} \cdot \mathrm{cm}^{-2}$, but field-grown leaves ranged from 20 to $80 \mu \mathrm{g} \cdot \mathrm{cm}^{-2}$. Thus, a measurement of 64 SPAD units could represent a 4-fold difference in TCHL, depending on the leaf set considered.

Again, in 1988, the models differed for greenhouse- and field-grown leaves (Expts. 2, 5, 6 vs. 4). In the field (Expt. 4), the relationship between SPAD and TCHL was not significant at $P=0.05$ (Table 1). Spring 1988 was cool in Blacksburg, Va., and mite populations remained relatively low, resulting in less of a reduction in TCHL than in 1987 and a weaker correlation. The slopes, but not the intercepts of the models, differed for the greenhouse-grown leaf sets between 1987 and 1988 (Expts. 1 vs. 2, 5, and 6). In 1988, the models had lower coefficients of determination than in 1987, probably because of the smaller ranges in SPAD measured in 1988 (Table 1). The three leaf sets grown in the greenhouse in 1988 (Expts. 2, 5 , and 6) had equivalent models.

The disparity in the models between experiments may partly be due to differences in leaf thickness. Field-grown leaves are typically thicker than greenhouse-grown leaves, and this is supported by the higher SLW values for the field-grown leaves (Table 1). The estimation of TCHL with the SPAD over time may be confounded by changes in SLW. However, there are differences in models among leaf sets with similar ranges of SLW and SPAD, indicating that other factors may influence the relationship between SPAD and TCHL.

The SPAD-501 meter has been suggested as a useful instrument for nondestructive determination of TCHL in experiments dealing with multiple measurements on the same leaf over time. Within an experiment, the SPAD meter is able to determine relative color differences between treatments due to TCHL, and it was an effective tool for evaluating chlorosis due to ozone damage in tomato (Tenga et al,, 1989). Previous research demonstrated the need for separate models for each plant species and individual meter. Our results indicate that, within a cultivar, growing conditions must also be considered in model development. Marquard and Tipton (1987), however, obtained a highly significant relationship $\left(R^{2}=0.89\right)$ on a range of species grown under full sun or heavy shade to induce an extreme range in TCHL. Few studies are conducted on plant material varying so widely in TCHL, and our results indicate that the SPAD and TCHL relationship has greater limitations within more reasonable ranges. For predictive purposes, the relationship between SPAD and TCHL must be determined for each experiment.

\section{Literature Cited}

Arnon, D.I. 1949. Copper enzymes in isolated chloroplasts. Polyphenoloxidase in Beta vul- garis. Plant Physiol. 24:1-15.

Marquard, R.D. and J.L. Tipton. 1987. Relationship between extractable chlorophyll and an in situ method to estimate leaf greenness. HortScience 22:1327.

Montgomery, D.C. and E.A. Peck. 1982. Introduction to linear regression analysis. Wiley, New York.

Tenga, A.Z., B.A. Marie, and D.G. Ormond. 1989. Leaf greenness meter to assess ozone injury to tomato leaves. HortScience 24:514.

Yadava, U.L. 1986. A rapid nondestructive method to determine chlorophyll in intact leaves. HortScience 21:1449-1450.

HortSCIENCE 25(3):331-334. 1990.

\title{
Net Photosynthesis, Specific Leaf Weight, and Flowering of Peach as Influenced by Shade
}

\author{
Richard P. Marini ${ }^{1}$ and Donald L. Sowers ${ }^{2}$ \\ Department of Horticulture, Virginia Polytechnic Institute and State \\ University, Blacksburg, VA 24061
}

Additional index words. photosynthetic photon flux, Prunus persica

Abstract. 'Redhaven' peach [Prunus persica (L.) Batsch] trees were shaded to five light levels $[100 \%, 45 \%, 23 \%, 17 \%$, and $9 \%$ photosynthetic photon flux (PPF)] for four different periods. Net photosynthesis (Pn), measured under the various shade levels, increased nonlinearly with increasing percent PPF. After 18 days of shading, specific leaf weight (SLW) was positively and linearly related to percent PPF. After shade removal, Pn and SLW returned to control levels in 26 and 4 days, respectively. Flower density was positively related to percent PPF when trees were shaded from 16 June to 4 July or 4-31 July, but not from 31 July to 30 Sept. of the previous year.

Orchard profitability depends on efficient absorption and use of light. Productivity of young orchards has been improved by increasing tree density (Erez, 1982; Layne and Tan, 1984), but as plantings mature, shading may become a problem. Shading reduced

Received for publication 22 May 1989. The cost of publishing this paper was defrayed in part by the payment of page charges. Under postal regulations, this paper therefore must be hereby marked advertisement solely to indicate this fact.

${ }^{1}$ Associate Professor.

${ }^{2}$ Research Technician flower bud initiation (Cain, 1971), fruit size and quality (Jackson et al., 1971; Seeley et al., 1980), and plant fresh weight (Barden, 1974) of apple. Photosynthetic characteristics of apple (Barden, 1974) and peach (Kappel and Flore, 1983) leaves were influenced by exposure to diverse light environments. Compared to sun-grown leaves, shade-grown leaves generally had lower net photosynthetic $(\mathrm{Pn})$ rates at saturating light levels and lower dark respiration rates and specific leaf weight (SLW). These characteristics not only depended on the light regime under which leaves developed, but also were influenced 